\title{
EFFECTS OF DIFFERENT RICE PLANTING DURATION ON ORGANIC CARBON COMPONENTS AND CARBON POOL MANAGEMENT INDEX OF SALINE-ALKALINE SOIL IN WESTERN JILIN PROVINCE, CHINA
}

\author{
LIU, Q. ${ }^{1}-$ TANG, J. ${ }^{2 *}$ \\ ${ }^{1}$ College of Landscape Architecture, Changchun University, Changchun 130012, China \\ ${ }^{2}$ College of New Energy and Environment, Jilin University, Changchun 130012, China \\ *Corresponding author \\ e-mail: hamiqi.365@163.com; phone:+86-181-0431-1389
}

(Received 26 $6^{\text {th }}$ Nov 2020; accepted $18^{\text {th }}$ Mar 2021)

\begin{abstract}
The soil carbon pool management index is an important quantitative index to characterize soil carbon change. It is of great significance to study the change process of easily oxidized organic carbon in the soil and carbon pool management index can be used in the case of saline-alkali fields of western Jilin province to understand the evolution of soil quality and evaluate its effects during ecological restoration. The temporal and spatial evolution characteristics of soil organic carbon (SOC), readily oxidized organic carbon (ROOC), non-readily oxidized organic carbon (NROOC) and carbon pool activity (A), carbon pool activity index (AI), carbon pool management index (CMI) and carbon pool index (CPI) in salinealkali paddy fields in western Jilin, China were analyzed. The results showed that the soil layer and rice growth stage were the main factors affecting the changes in soil carbon pool, and the CPI and CMI increased with the increase of cultivation time. The soil ROOC, NROOC is closely related to SOC and is an important part of soil SOC, and obviously depends on the input, fixation, transformation and decomposition of surface carbon sources.
\end{abstract}

Keywords: saline-alkali rice field, rice growth stages, easily oxidized organic carbon, carbon pool management index, influencing factors

\section{Introduction}

Soil readily oxidizable organic carbon is an important component of soil carbon pool, and is easily degraded by oxidation in soil (Ya et al., 2013). The temporary fluctuation of soil organic matter mainly occurred in the easily oxidized part, and the ratio of Rooc to organic carbon could indicate the soil quality and the rate of soil organic carbon oxidation (Cao et al., 2019). Therefore, Rooc is an important index of soil fertility change, which can indicate the dynamic change of soil organic matter. It was found that the organic carbon that could be oxidized by $333 \mathrm{mmol} \cdot \mathrm{L}^{-1} \mathrm{KMnO}_{4}$ changed the most when growing crops, and the organic carbon that could be oxidized by $333 \mathrm{mmol} \cdot \mathrm{L}^{-1} \mathrm{KMnO}_{4}$ was called active organic carbon, while the organic carbon that could not be oxidized was called inactive organic matter (Zhao et al., 2019). Active organic carbon can be used as an indicator of early changes in organic carbon, while non-active organic carbon can be used as an indicator of soil long-term accumulation and carbon sequestration (Liu et al., 2019). Soil carbon pool management index is a quantitative index to characterize soil carbon change. It is based on soil total organic carbon and easily oxidized organic carbon (Lefroy et al., 1993). The soil carbon pool management index is obtained by calculation. Ever since the concept of carbon management index was put forward, it has often been used to monitor the effectiveness of soil carbon pool dynamics and evaluate the management level of soil quality (Tang et al., 
2014). The effects of different land use (Qiu et al., 2009), tillage management (Lv et al., 2014 ) etc. on soil carbon pool have been widely used. Therefore, under the background of the sharp change of global climate and the sharp increase of greenhouse effect, it is of great significance to clarify the change characteristics and evolution law of the management index of easily oxidized organic carbon and carbon pool in saline-alkali paddy soil for the rational utilization of saline-alkali soil, soil fertilization and soil carbon sequestration. The saline-alkali land is widely distributed throughout the world, covering more than 30 countries on six continents, with a total area of about $9.56 \times 10^{9}$ ha. Australia accounted for $37 \%$, the former Soviet Union for $18 \%$ and China for $10 \%$. The saline-alkali land of Songnen Plain is the concentrated distribution area of saline-alkali land in China. The west of Jilin Province is located on the south side of Songnen Plain, which is a serious disaster area of soda-alkaline desertification. In order to promote the development and utilization of saline-alkali land, rice was planted in part of the land to improve saline-alkali land. (Zhang et al., 2016a). At present, there are few studies on soil carbon pool index of saline-alkalized paddy field under different rice cultivation years. Therefore, the change characteristics of soil carbon pool management index and its evolution law during the maturation of salinealkali rice field are discussed.

\section{Materials and methods}

\section{Study description}

The saline-alkali soil area in western Jilin of China was once a large inland lake basin in geological history, and the lake water was abundant and withered many times, which made the soluble salt in the parent rock of the highland in the basin converge with the runoff in the closed-flow lowland, forming a large area of saline-alkali soil deposition (Tang et al., 2012a). Rice plantation is adopted as the main method for the improvement as well as repair and utilization of saline alkali land in this area. Here, the Qianguoerluos County Irrigation District $\left(123^{\circ} 35^{\prime}-125^{\circ} 18^{\prime} \mathrm{E}, 44^{\circ} 17^{\prime}-45^{\circ} 28^{\prime} \mathrm{N}\right)$ is one of the four major irrigation districts in Northeast China. The annual average number of sunny days is 110 days, the annual average sunshine hours is $2879 \mathrm{~h}$, the annual average temperature is $4.5^{\circ} \mathrm{C}$. The initial frost period is generally in the middle and late September, the final frost period is generally from the end of April to the beginning of May, and the frost-free period is 130-140 days. The average annual precipitation is $400-500 \mathrm{~mm}$. The annual evaporation is more than $1200 \mathrm{~mm}$ (Tang et al., 2011). Time series study is a powerful tool to understand the change and evolution of soil texture, so in order to make the sample land more representative and the test results more universal, according to the soil type map and the land use type map, combined with the field investigation, according to the paddy field tillage history, and to determine the management method, soil properties basically involved 5 different cultivation years, one year (S1), 10 years (S2), 20 years (S3), 30 years (S4), 50 years (S5), were determined as test plots based on soil type maps and land use type maps, combined with field surveys and based on paddy field tillage history (Fig. 1). The plots were unified into single-planted rice soil, and the management of each plots was consistent. The base fertilizer was urea, phosphate and potash.

\section{Sample collection and analysis}

Soil sampling was carried out at different growth stages (seedling stage, tillering stage, heading stage, seed setting stage, mature stage) of rice growth. The soil samples 
of $0-10,10-20,20-30,30-40,40-50 \mathrm{~cm}$ soil layer were collected according to the $\mathrm{S}$ sampling method, 180 sampling points were set. The samples of the same soil layer at each sampling point were mixed to remove plant residues and roots from the soil and placed in plastic bags. Then the soil samples were stored in the incubator under $4{ }^{\circ} \mathrm{C}$ conditions. After all the soil was collected, the soil was brought back to the laboratory for testing.

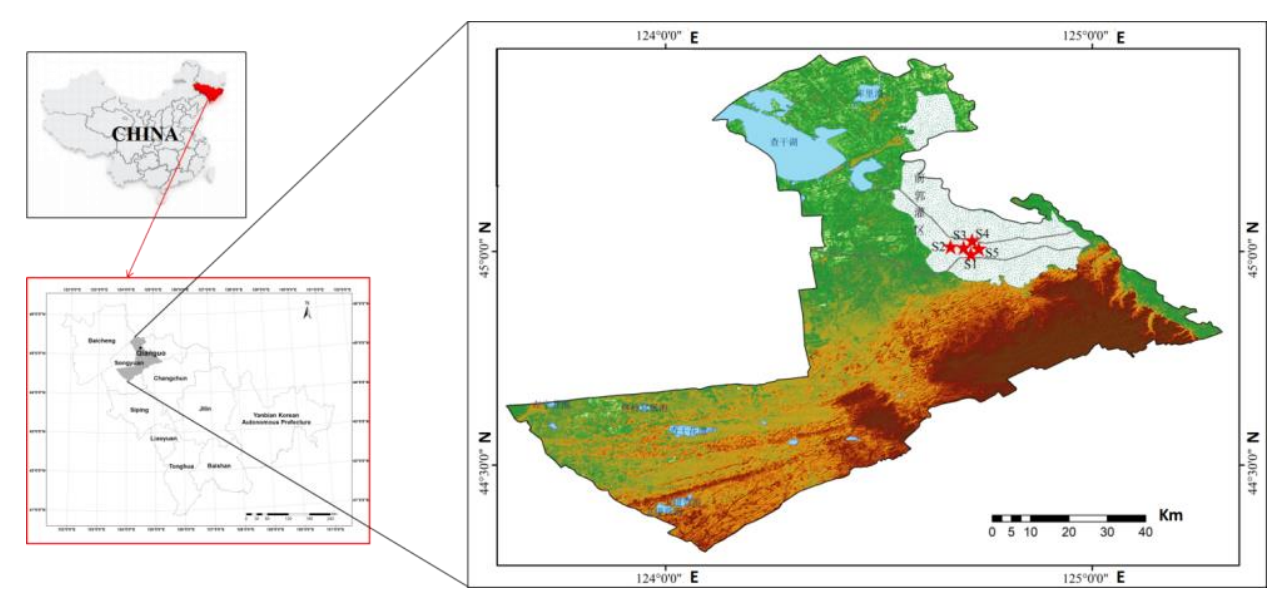

Figure 1. The location of the study area and the distribution of the sampling points

Soil organic carbon (SOC) was determined by potassium dichromate external heating (Bao, 2000). Readily oxidized organic carbon (ROOC) was determined by $\mathrm{KMnO}_{4}$ oxidation method (Zhou et al., 2019).

The management index of carbon pool is calculated by Blair and Lefroy, and the calculation formula is as follows:

$$
\begin{gathered}
\text { NROOC }=\mathrm{SOC}-\mathrm{ROOC} \\
\mathrm{A}=\mathrm{ROOC} / \mathrm{NROOC} \\
\mathrm{AI}=\mathrm{TSOCa} / \mathrm{RSOCa} \\
\mathrm{CPI}=\mathrm{TSOC} / \mathrm{RSOC} \\
\mathrm{CMI}=\mathrm{AI} \times \mathrm{CPI} \times 100
\end{gathered}
$$

where SOC is soil organic carbon, ROOC is readily oxidized organic carbon, NROOC is non-readily oxidized organic carbon, A is carbon pool activity, AI is carbon pool activity index, TSOCa is tillage soil carbon pool activity, RSOCa is reference soil carbon pool activity, CPI is carbon pool index, TSOC is tillage soil organic carbon, RSOC is reference soil organic carbon, CMI is the carbon pool management index (Blair et al., 1995).

\section{Statistical analysis}

One-way ANOVA method is used to analyze the influence of three factors on soil carbon composition and carbon pool management index under single condition. 
Multivariate ANOVA was used to analyze the comprehensive differences of carbon composition and carbon pool management index caused by three factors: rice cultivation, soil layer and rice growth stage. Pearson correlation analysis is used to analyze the correlation between soil carbon components and carbon pool management indicators.

\section{Results}

\section{Distribution of soil carbon content}

As can be seen from Figure 2, the soil SOC content showed a decreasing trend: $\mathrm{S} 5>\mathrm{S} 4>\mathrm{S} 3>\mathrm{S} 2>\mathrm{S} 1$. The SOC content of S5 was significantly higher than S1 $(p<0.05)$, and the soil SOC content of S5 increased gradually with the extension of rice cultivation, the results showed that longer rice growing period and lower saltalkali stress were beneficial to soil SOC accumulation. During the rice growing stage, the soil SOC content decreased firstly and then increased, and the soil SOC content was the lowest in tillering stage.

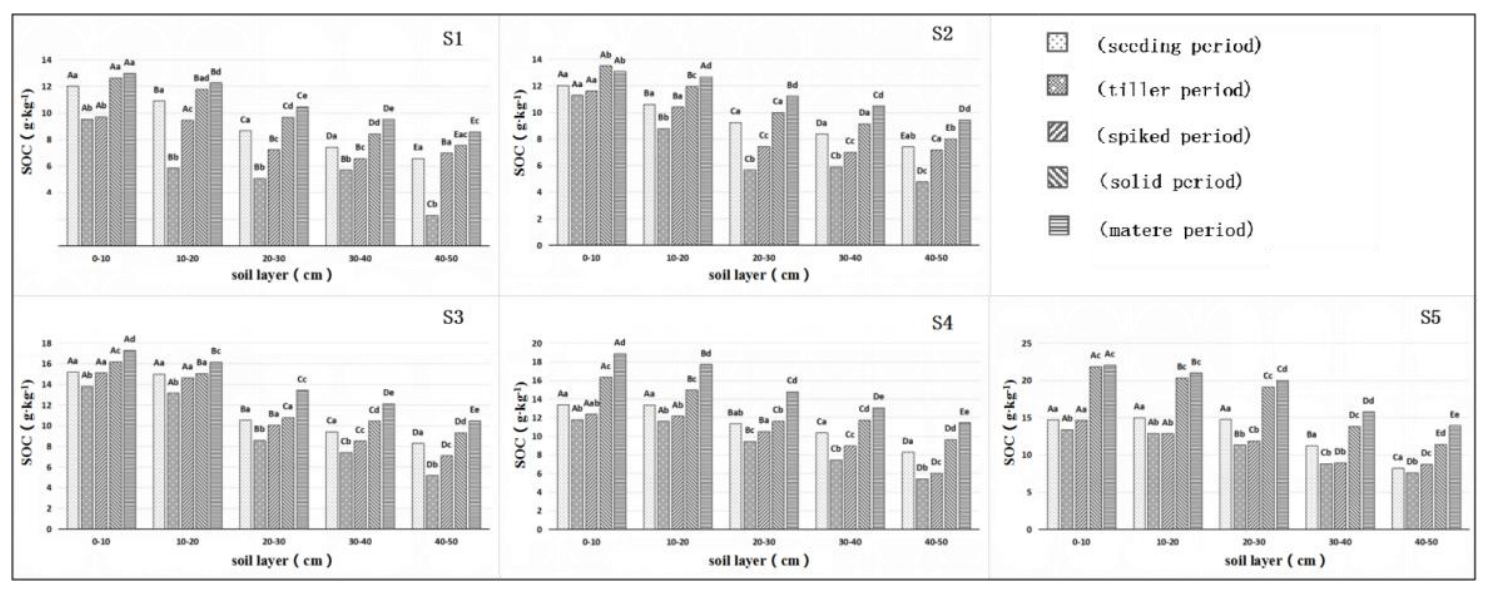

Figure 2. The soil SOC content and distribution characteristics

Figures 3 and 4 show that, Soil ROOC and NROOC content increased significantly with planting years. The soil ROOC content of S1, S2, S3, S4 and S5 were 0.47$4.16 \mathrm{~g} \cdot \mathrm{kg}^{-1}, 1.31-5.41 \mathrm{~g} \cdot \mathrm{kg}^{-1}, 2.10-7.89 \mathrm{~g} \cdot \mathrm{kg}^{-1}, 2.05-7.47 \mathrm{~g} \cdot \mathrm{kg}^{-1}$ and $2.24-7.91 \mathrm{~g} \cdot \mathrm{kg}^{-1}$, respectively. The soil ROOC content increased with the increase of rice cultivation years, the soil ROOC content of S5 was significantly higher than S1, the soil ROOC content of S4 was slightly lower than S3. The soil NROOC content was lower than ROOC. The soil NROOC content of S1, S2, S3, S4 and S5 were $1.83-8.94 \mathrm{~g} \cdot \mathrm{kg}^{-1}, 3.46-$ $8.51 \mathrm{~g} \cdot \mathrm{kg}^{-1}, 3.09-9.75 \mathrm{~g} \cdot \mathrm{kg}^{-1}, 3.38-11.39 \mathrm{~g} \cdot \mathrm{kg}^{-1}$ and $4.75-14.45 \mathrm{~g} \cdot \mathrm{kg}^{-1}$, respectively. The soil NROOC content of S5 was significantly higher than S1, and characteristics of small differences between S3 and S4 were observed. The soil NROOC content was lower in tillering stage and higher in spike-pumping stage, and its distribution law was basically consistent with the distribution characteristics of SOC. The results showed that the soil NROOC content of rice was higher in surface soil, the NROOC content of $0-10 \mathrm{~cm}$ soil layer was close to 2 times that of 40-50 cm soil layer, and the NROOC content of 10-20 $\mathrm{cm}$ soil layer was slightly lower than $0-10 \mathrm{~cm}$, but the decrease was not large. 


$$
\text { - } 2217 \text { - }
$$
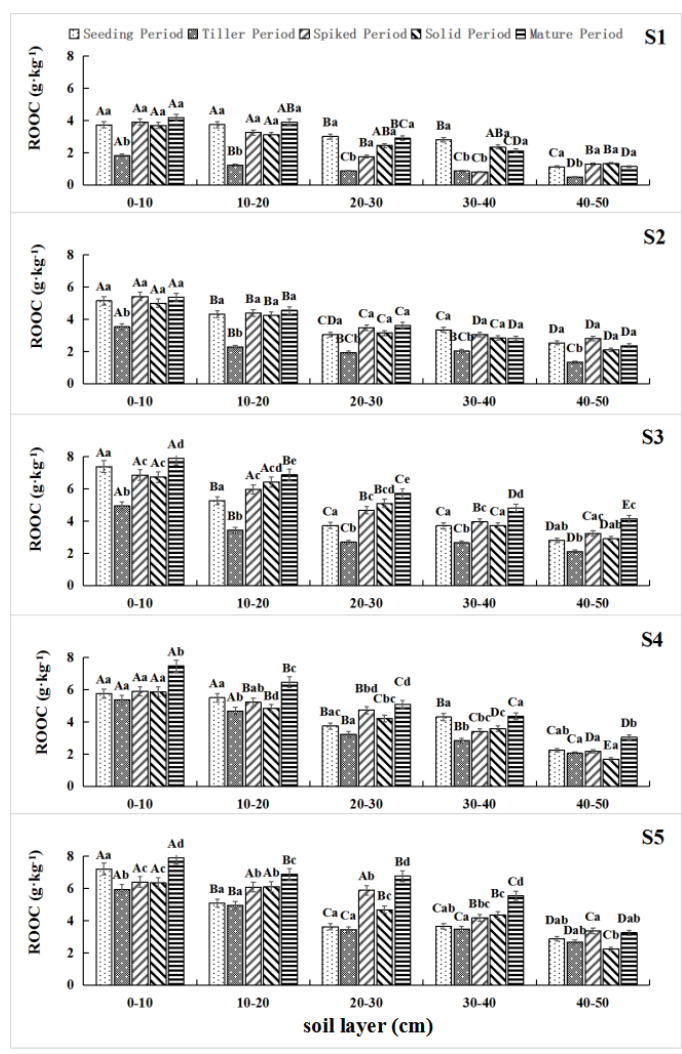

Figure 3. The soil ROOC content and distribution characteristics
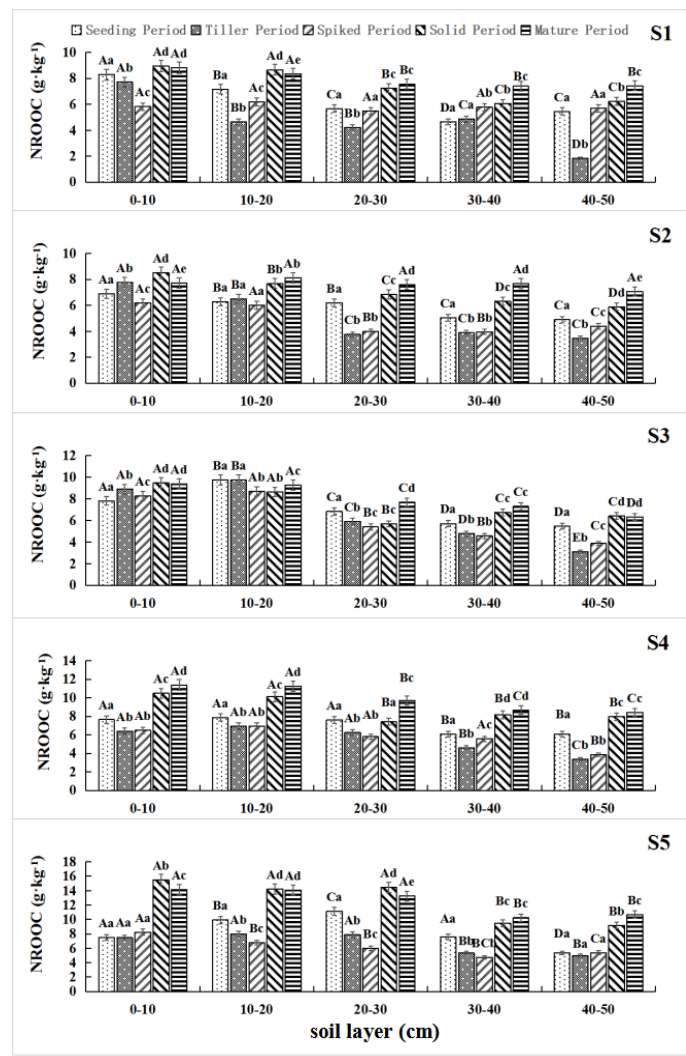

Figure 4. The soil NROOC content and distribution characteristics 


\section{Changes in soil carbon pool management indicators}

Using saline-alkali wasteland soil in Qianguo County as reference soil, the carbon pool activity (A), carbon pool activity index (AI), carbon pool index (CPI) and carbon pool management index (CMI) of paddy field soil with different rice cultivation years were calculated by space-time substitution method. The results are shown in Figures 5, 6,7 and 8.

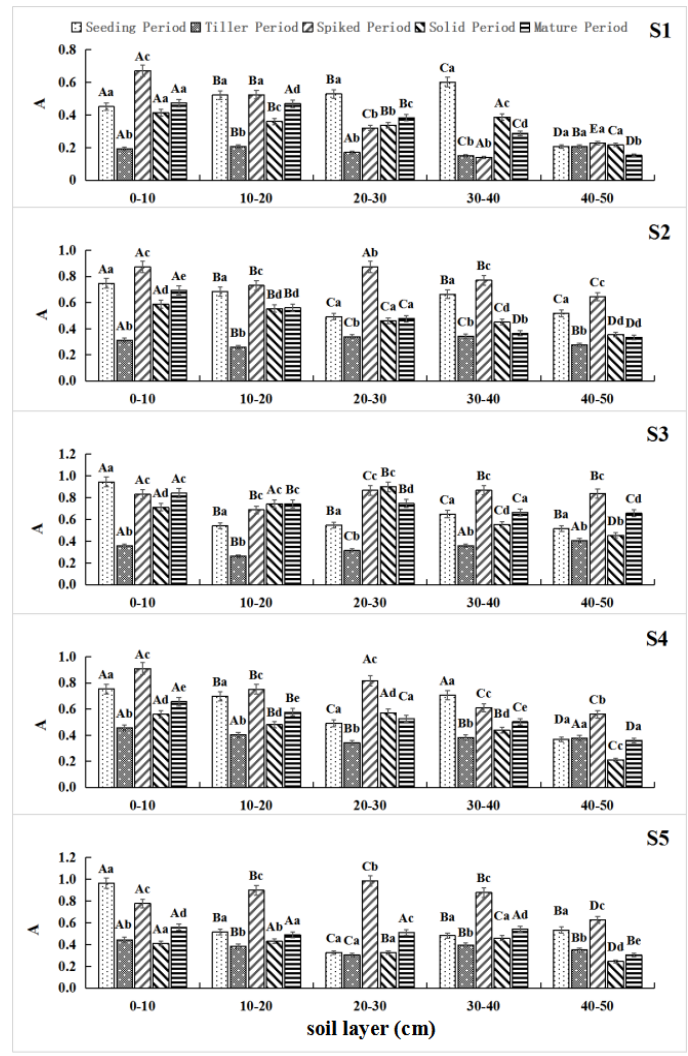

Figure 5. Distribution of A in rice during different growing stages

The soil A index values of S1, S2, S3, S4 and S5 were 0.14-0.67, 0.26-0.87, 0.260.94, 0.34-0.91 and 0.30-0.96, respectively. During the rice growing stage, the soil A index value ranged from 0.56 to 0.98 at the rice heading stage, which was the highest value in the whole growing stage and more than twice the value of the soil A index at the tillering stage. The change of A index value of S1 soil in rice growing stage is different from other years. This may be closely related to the time of rice planting and human disturbance, a preliminary change in the nature of the land, so that the soil to undertake root exudates type changes. As a result, the formation of soil carbon pool activity will be different (Guo et al., 2014).

The soil AI index value of different rice cultivation years was slightly higher in heading period, but with the extension of rice cultivation years, the fluctuation of AI index was more intense, the law was not obvious, and there was no obvious law between soil layers.

The soil CPI index increased gradually with the increase of rice cultivation years. The values of CPI of S1, S2, S3, S4 and S5 were 0.28-1.04, 0.53-1.10, 0.58-1.36, 0.56-1.44 and 
0.68-1.54, respectively. During the rice cultivation years, the CPI values of mature soil were higher, and those of tillering soil were lower. In addition, the CPI values of $10-20 \mathrm{~cm}$ soil layers of S2 and S3 were higher than that of other soil layers, the CPI value of $20-30 \mathrm{~cm}$ soil layer of S4 and S5 were higher than that of other soil layers.

The soil CMI index of S1, S2, S3, S4 and S5 were 16.56-222.48, 26.91-323.25, $31.07-130.67,37.02-129.08$ and 27.01-91.65, respectively. With the growing of rice, the soil CMI index of S2 was higher than S1, and the soil CMI index of S3 was similar to S4. The results showed that the soil CMI index of saline-alkali rice field fluctuated greatly. In this study, the maximum value of soil CMI index was reached when rice was planted to 20-30 years, and then began to decrease slowly. During rice growth stages, the soil CMI index of heading stage was higher than that of other growth stages.

\section{Coupling relationship between soil SOC, ROOC and NROOC and carbon pool management index}

Table 1 shows the correlation among organic carbon, readily oxidizable organic carbon, steady-state carbon and carbon pool management indicators. The soil SOC, ROOC and NROOC of S1, S2, S3, S4 and S5 were significantly correlated with CMI index, and there were no significant correlation between the soil ROOC and index A. The soil ROOC of S2, S3, S4 and S5 were significantly correlated with index A $(P<0.05)$, and the correlation coefficient was greater between the soil ROOC and index A with the extension of rice cultivation years. The soil SOC of S4 and S5 were significantly correlated with CPI $(P<0.05)$.

Table 1. Correlation analysis of soil SOC, ROOC, NROOC and carbon reservoir management index

\begin{tabular}{c|c|c|c|c|c}
\hline $\begin{array}{c}\text { Sample } \\
\text { number }\end{array}$ & Index & A & AI & CMI & CPI \\
\hline \multirow{3}{*}{ S1 } & SOC & -0.240 & 0.313 & $-0.402^{*}$ & $-0.419^{*}$ \\
& ROOC & -0.080 & 0.255 & $-0.473^{*}$ & $-0.529^{* *}$ \\
& NROOC & 0.284 & -0.316 & $0.887^{* *}$ & 0.299 \\
\hline \multirow{3}{*}{ S2 } & SOC & 0.311 & $-0.430^{*}$ & $0.764^{* *}$ & -0.150 \\
& ROOC & $0.522^{* *}$ & -0.212 & $0.502^{*}$ & 0.032 \\
& NROOC & -0.050 & $-0.447^{*}$ & $0.827^{* *}$ & -0.126 \\
\hline \multirow{3}{*}{ S3 } & SOC & 0.335 & 0.026 & $0.629^{* *}$ & 0.325 \\
& ROOC & $0.645^{* *}$ & $0.397 *$ & $0.460^{*}$ & $0.499^{*}$ \\
& NROOC & 0.021 & -0.251 & $0.667^{* *}$ & 0.095 \\
\hline \multirow{3}{*}{ S4 } & SOC & 0.314 & 0.110 & $0.620^{* *}$ & $0.517^{* *}$ \\
& ROOC & $0.672^{* *}$ & $0.462^{*}$ & $0.423^{*}$ & $0.465^{*}$ \\
& NROOC & 0.042 & -0.092 & $0.735^{* *}$ & $0.443^{*}$ \\
\hline \multirow{3}{*}{ S5 } & SOC & -0.136 & -0.275 & $0.895^{* *}$ & $0.588^{*}$ \\
& ROOC & $0.883^{* *}$ & 0.324 & $0.413^{*}$ & $0.643^{* *}$ \\
& NROOC & 0.013 & -0.312 & $0.443^{*}$ & $-0.450^{*}$ \\
\hline
\end{tabular}

* indicates significant difference $(\mathrm{P}<0.05)$, ** represents a very significant difference $(\mathrm{P}<0.01)$. SOC, organic carbon; ROOC, readily oxidized organic carbon, NROOC, non-readily oxidized organic carbon, A, carbon pool activity, AI, carbon pool activity index, CPI, carbon pool index, CMI, carbon pool management index 


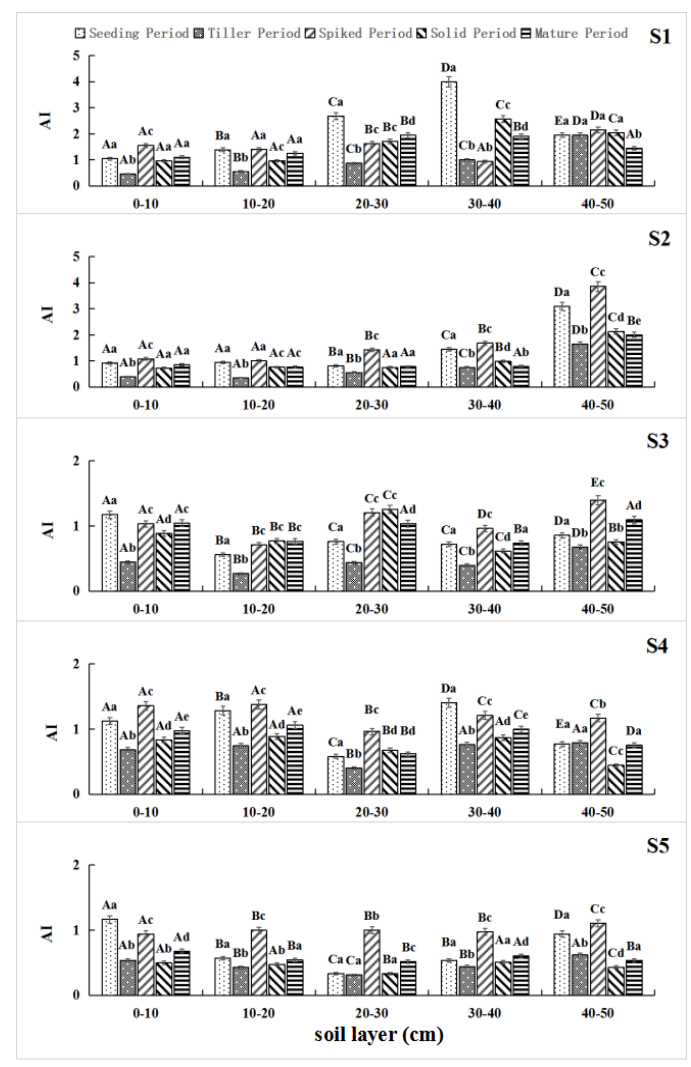

Figure 6. Distribution of AI in rice during different growing stages
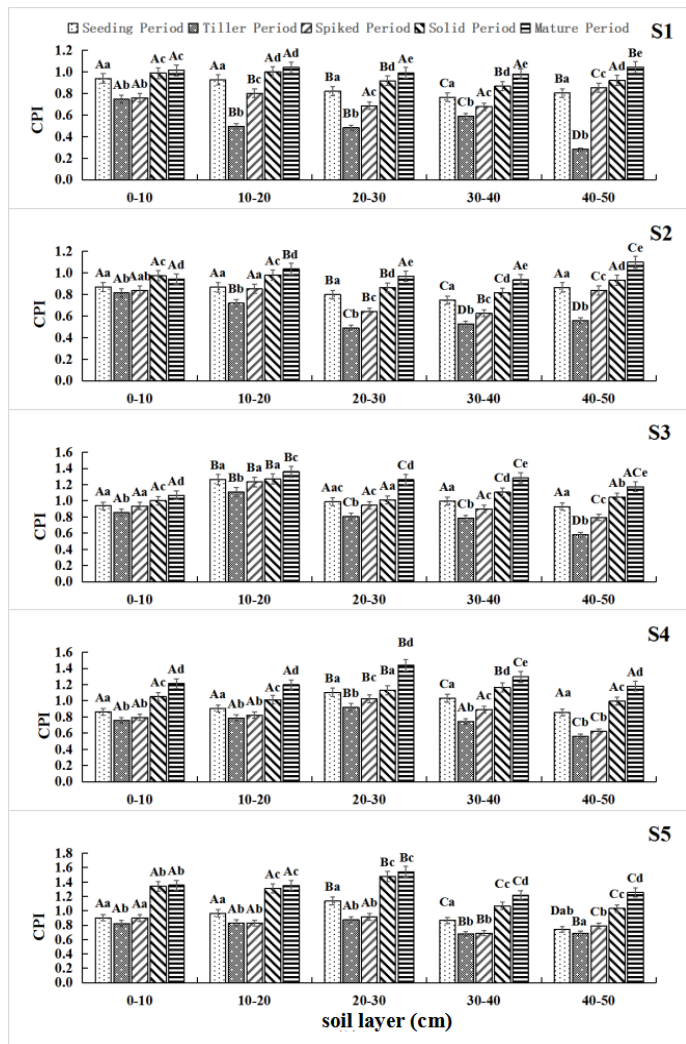

Figure 7. The soil CPI content and distribution characteristics 


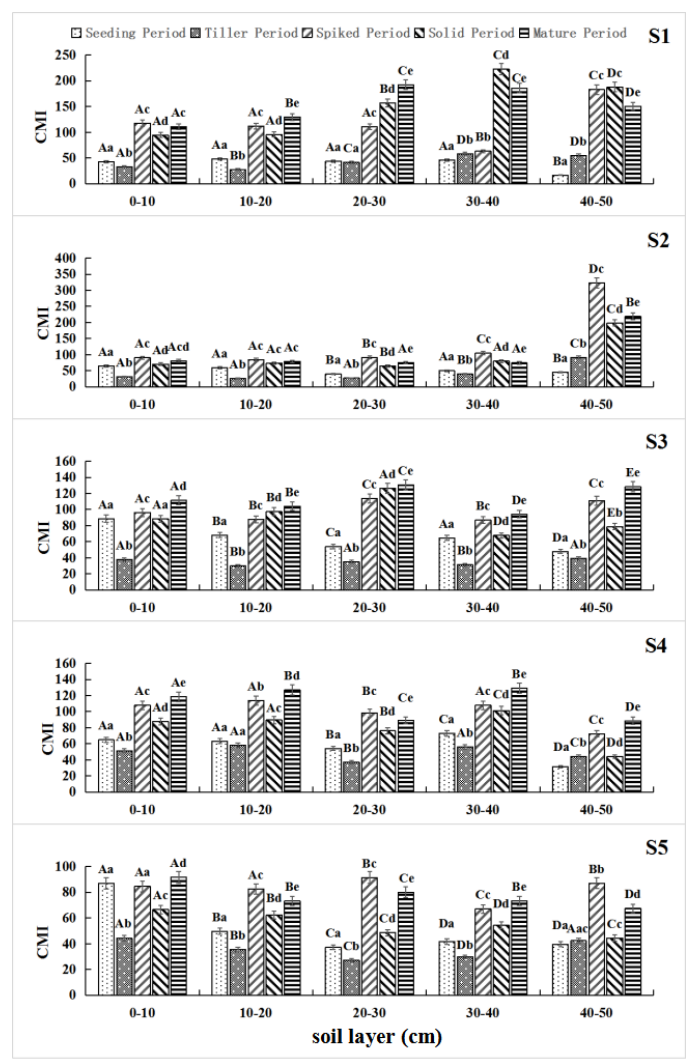

Figure 8. The soil CMI content and distribution characteristics

\section{Factors influencing the management index of carbon pool}

Table 2 shows the effects of soil layer, the rice cultivation years and rice growth stages on the carbon pool management index. The results showed that soil layer as an independent source of variation had a significant effect on AI and CMI $(P<0.001)$, and the number of rice cultivation years and rice growth stages as the independent source of variation had a significant effect on soil management indexes $(P<0.001)$.

\section{Discussion}

Characteristics and contribution of carbon accumulation in soil steady state during saline-alkali rice maturing

The dynamic balance of soil carbon pool is closely related to crop growth and fertilization management and directly affects soil fertility and crop yield (Cuo et al., 2014). Actually, agricultural production (e.g. years of soil tillage, management of fertilization, return of plant residues or organic materials, etc.) causes the initial changes in the soil carbon pool mainly by easy decomposition and mineralization. Currently, some scholars have tried to use soil organic carbon sublibrary to indicate total carbon change (Ma et al., 2019; Sun et al., 2015). The change of soil carbon pool mainly occurs in the active carbon pool (Kong et al., 2019). Therefore, they are important for soil carbon conversion, and it is closely related to soil productivity. Dalal and others think that it is better to use unstable carbon (Labile C) to indicate the change of soil carbon pool (Dalal et al., 1986). According to Su Jing and other studies, 
the main increase is inactive organic carbon content ( $\mathrm{Su}$ et al., 2005). Distribution of NROOC in general soils is between 75 and 85\%, and different ecosystems have different NROOC contents in soil (Ma et al., 2019; Li et al., 2006). In this study, during the rice growth stage, the proportion of the soil NROOC in saline-alkali paddy fields with different rice cultivation years was about 52.4-87.72. With the extension of rice, the soil ROOC and NROOC are increasing, and the NROOC content is higher than ROOC. In the process of rice cultivation years, most of the main carbon in the soil is converted into inactive parts and stored in soil (Mao, 2019). The soil NROOC content of different rice cultivation years also showed seasonal variation law, because of the difference of exogenous carbon input and soil microbial activity in different rice cultivation years.

Table 2. Multifactorial variance analysis of carbon bank management index

\begin{tabular}{|c|c|c|c|c|c|c|}
\hline Index & Source of variation & $\begin{array}{l}\text { Sum of } \\
\text { squares }\end{array}$ & $\begin{array}{l}\text { Degree of } \\
\text { freedom }\end{array}$ & Mean square & $\mathbf{F}$ & $\mathbf{P}$ \\
\hline \multirow{7}{*}{ A } & Soil layer & 0.558 & 4 & 0.139 & 38.124 & 0.001 \\
\hline & Reclamation time & 1.159 & 4 & 0.29 & 79.2 & $*$ \\
\hline & Growth stage & 1.992 & 4 & 0.498 & 136.148 & $*$ \\
\hline & Soil layer $*$ Reclamation time & 0.077 & 15 & 0.005 & 1.402 & 0.377 \\
\hline & Reclamation time $*$ Growth stage & 0.293 & 16 & 0.018 & 5.002 & 0.042 \\
\hline & Soil layer * Growth stage & 0.517 & 16 & 0.032 & 8.834 & 0.012 \\
\hline & Soil layer * Reclamation time * Growth stage & 0.555 & 60 & 0.009 & 2.531 & 0.15 \\
\hline \multirow{7}{*}{ AI } & Soil layer & 7.321 & 4 & 1.83 & 168.896 & $*$ \\
\hline & Reclamation time & 13.354 & 4 & 3.339 & 308.083 & $*$ \\
\hline & Growth stage & 7 & 4 & 1.75 & 161.483 & $*$ \\
\hline & Soil layer * Reclamation time & 11.159 & 15 & 0.744 & 68.653 & $*$ \\
\hline & Reclamation time $*$ Growth stage & 1.895 & 16 & 0.118 & 10.931 & 0.008 \\
\hline & Soil layer * Growth stage & 3.551 & 16 & 0.222 & 20.48 & 0.002 \\
\hline & Soil layer * Reclamation time * Growth stage & 6.266 & 60 & 0.104 & 9.637 & 0.009 \\
\hline \multirow{7}{*}{ CPI } & Soil layer & 0.282 & 4 & 0.071 & 11.138 & 0.011 \\
\hline & Reclamation time & 1.123 & 4 & 0.281 & 44.291 & $*$ \\
\hline & Growth stage & 3.309 & 4 & 0.827 & 130.548 & $*$ \\
\hline & Soil layer * Reclamation time & 0.72 & 15 & 0.048 & 7.574 & 0.017 \\
\hline & Reclamation time $*$ Growth stage & 0.166 & 16 & 0.01 & 1.634 & 0.308 \\
\hline & Soil layer * Growth stage & 0.336 & 16 & 0.021 & 3.313 & 0.095 \\
\hline & Soil layer * Reclamation time * Growth stage & 0.192 & 60 & 0.003 & 0.504 & 0.906 \\
\hline \multirow{7}{*}{ CMI } & Soil layer & 18296.604 & 4 & 4574.151 & 62.369 & $*$ \\
\hline & Reclamation time & 24126.885 & 4 & 6031.721 & 82.243 & $*$ \\
\hline & Growth stage & 112007.641 & 4 & 28001.91 & 381.81 & $*$ \\
\hline & Soil layer $*$ Reclamation time & 46784.172 & 15 & 3118.945 & 42.527 & $*$ \\
\hline & Reclamation time $*$ Growth stage & 22854.251 & 16 & 1428.391 & 19.476 & 0.002 \\
\hline & Soil layer * Growth stage & 29025.917 & 16 & 1814.12 & 24.736 & 0.001 \\
\hline & Soil layer $*$ Reclamation time $*$ Growth stage & 32085.276 & 60 & 534.755 & 7.291 & 0.017 \\
\hline
\end{tabular}

* indicates significant difference $(\mathrm{P}<0.001)$. A, carbon pool activity, AI, carbon pool activity index, CPI, carbon pool index, CMI, carbon pool management index 


\section{Response of soil carbon reservoir management index to organic carbon accumulation in saline-alkali paddy field}

The change of land use mode can lead to the change of tillage system, which will affect the balance of soil organic matter and change the decomposition rate of soil organic carbon (Tang et al., 2012b; Shen et al., 2000). In this study, the effect of planting years on soil carbon pool management index was obvious, and the soil A index value of different rice cultivation years was different. The soil A index value of 50 years was higher than that of the newly planted rice, which indicated that the carbon of salinealkali paddy soil did not age, which was beneficial to carbon transformation.

The soil CPI index value increased gradually with the extension of rice cultivation years, which was basically consistent with the research of Wu et al (2015). The results showed that the soil CPI value increased after rice cultivation in dry land and wasteland. It shows that rice cultivation can effectively improve the carbon sink function of salinealkali soil during the ripening process of saline-alkali rice field.

The soil CMI index value combined with soil carbon pool index and soil activity index, it can be sensitive to reflect and monitor soil organic carbon change index (Xu et al., 2006), and it can reflect external conditions on the quantity and quality of each component in carbon pool. The rise in the carbon pool management index indicates an increase in soil fertility, while a decline indicates a decline in soil fertility (Qiu et al., 2009). According to some studies, the initial change of soil carbon pool caused by agricultural production management measures and land use mode is mainly activated carbon part, which further affects soil carbon pool management index (Zhang et al., 2016b).

In this study, carbon pool activity (A) increases gradually with the rice cultivation years from the carbon pool management indices. During the rice cultivation, the soil carbon pool activity in seedling stage and heading stage is large, it shows that the soil quality improved in the process of soil maturation. The return of straw to the field is beneficial to the improvement of soil active carbon content and carbon pool management index in the tillage layer. The soil carbon pool management index is vulnerable to fertilization and farming years according to $\mathrm{Wu}$ Jianfu and other studies (Wu et al., 2013). In this study, the soil CMI index values increased gradually with the increase of rice cultivation, S2 above S1 level, and continued to increase with the extension of rice cultivation years, to show that reasonable rice cultivation can effectively improve soil CPI and CMI, but then the soil CMI began to slow down, because of farming provides a more suitable environment for microbes. As a result, the decomposition rate of soil organic carbon increased (Liu et al., 2017), so S5 soil CMI is lower than S4.

Sun Tao and others simulated the effect of planting years on the change of soil carbon pool in secondary saline-alkali soil based on CENTURY model (Sun et al., 2015). It was found that the total organic carbon of soil experienced a rapid rise, rapid decline and gradual steady change after planting Lycium barbarum. Therefore, the renewal and change of soil carbon pool caused by planting years may continue to be dynamic in the early decades of planting. On the other hand, it is found that the L, CPI and CMI of deep soil $(40-50 \mathrm{~cm})$ are lower than that of surface soil $(0-10 \mathrm{~cm})$, which is similar to that of Li et al. (2008). It shows that the carbon pool transformation and nutrient cycle of deep soil decrease slowly.

The main factors affecting the change of carbon pool management index were analyzed from three aspects: rice cultivation years, soil layer and rice growing stage. 
The results showed that soil layer had only significant effect on AI, CMI $(P<0.001)$, which indicated that the change of carbon pool activity in cultivated soil was obviously affected by section structure. Both rice cultivation years and rice growth stage have significant effects on A, AI, CPI and CMI, indicating that the renewal and evolution of soil carbon pool in saline-alkali rice field is more based on the influence of rice cultivation years and crop growth.

The correlation analysis showed that the soil SOC, ROOC and NROOC content of different rice cultivation years was significantly positively correlated in different rice growth stages, indicating that soil ROOC and NROOC were closely related to SOC, and was an important part of soil SOC, it obviously depended on the input, fixation, transformation and decomposition of surface carbon sources (Zhang et al., 2020). Further, it is clear that soil ROOC is a sensitive index to indicate soil carbon pool, which can reflect the change characteristics of soil organic carbon pool in the short term. Previous studies have shown that the soil CMI index can well indicate the change of soil quality and organic carbon (Zhang et al., 2019). The soil SOC and CMI index showed no significant correlation between tillering stage and heading stage. As a result, the soil CMI index can be used to evaluate the cumulative effect of soil carbon pool in rice cultivation.

\section{Conclusion}

The readily oxidized organic carbon to soil rice cultivation years and growing stage is obvious, which indicates that the stability of soil carbon pool is closely related to rice growth. Therefore, the feedback effect of plant and atmosphere on soil material circulation can further be studied, this provides a more comprehensive understanding of the process of the carbon bank cycle.

In the process of maturation of saline-alkali rice field, the content of soil NROOC increased significantly with the extension of rice cultivation years. The soil CMI index and the organic carbon content change obviously, showing that the soil CMI index increases first and then decreases with the extension of rice cultivation years. However, the carbon pool is in dynamic change during the maturation of saline-alkali rice field. The renewal and evolution of soil carbon pool is more based on the influence of rice cultivation and crop growth. Therefore, it is suggested that reasonable rice planting can improve the quality of soil carbon pool in saline-alkali paddy field.

Funding. This research was funded by National Natural Science Foundation of China (No.51179073, 41471152) and Changchun University Scientific Research and cultivation Fund (2019JBC27L40).

\section{REFERENCES}

[1] Bao, S. D. (2000): Soil Agrochemical Analysis. - China Agricultural Publishing House, Beijing.

[2] Biederbeck, B. O., Janzen, H. H., Campbell, C. A., Zentner, R. P. (1994): Labile soil organic matter as influenced by cropping practices in an arid environment. - Soil Biology \& Biochemistry 26(12): 1656-1674.

[3] Cao, P., Xu, Y., Zhu, J., Tian, Y. C., Feng, X. Z., Liu, Z. Y. (2019): Short-term effects of different cropping patterns on soil labile organic carbon fractions and yields of paddy fields. - Chinese Journal of Ecology 38(9): 2788-2798. 
[4] Dalal, R. C., Mayer, R. J. (1986): Long-term trends in fertility of soils under continuous cultivation and cereal cropping in Southern Queensland. IV loss of organic carbon from different density fractions. - Soil Res 24: 301-309.

[5] Guo, B. H., Fan, S. H., Du, M. Y. (2014): Effect of land-use type on soil labile carbon pool and carbon management index. - Chinese Journal of Ecology 33(3): 723-728.

[6] Kong, J. Q., Du, Z. Y., Yang, R., Su, Y. Z. (2019): Evolutionary characteristics of soil organic carbon storage in soil plough layer under a cropland reclamation process in desert oasis. - Chinese Journal of Applied Ecology 30(1): 180-188.

[7] Lefroy, R. D., Blair, C., Strong, W. M. (1993): Changes in soil organic matter with cropping as measured by organic carbon fractions from ${ }^{13} \mathrm{C}$ natural isotope abundance. Plant and Soil 155: 399-402.

[8] Li, L., Li, S. J., Zhang, H. L., Chen, F. (2006): Study on soil C pool management index of conversation tillage. - Journal of Soil and Water Conservation 20(3): 106-109.

[9] Liu, C., Sun, L., Zang, S. Y. (2017): Research progress on influencing factors of organic carbon in tillage soil. - Heilongjiang Science and Technology Information 3: 165-165.

[10] Liu, X., Li, S. Y., Peng, C. (2019): Effects of deep loosening and deep straw returning on soil organic carbon and its active fractions in black soil. - Soil Communication 50(3): 602-608.

[11] Lv, R. Z., Xiong, Y., Li, Y. J., Lv, Q., Huang, M. (2014): Effect of conservation tillage on soil carbon pool in farmland. - Journal of Soil and Water Conservation 28(4): 206209: 217.

[12] Ma, W. W., Li, G., Song, J., Yan, L. J., Wu, L. Y. (2019): Effect of vegetation degradation on soil organic carbon pool and carbon pool management index in the Gahai Wetland, China. - Acta Agrestia Sinica 27(3): 687-694.

[13] Mao, D. (2019): Advances in research on soil organic carbon in paddy field. - Journal of Green Science and Technology 6: 19-22.

[14] Qiu, L. P., Zhang, X. C., Cheng, J. M. (2009): Effects of land-use type on soil organic matter and carbon management index in Ziwuling area. - China Environmental Science 29(1): 84-89.

[15] Su, J., Zhao, S. W., Ma, J. D., Yang, Y. H., Liu, N. N. (2005): Influence of man-made vegetation on carbon pool in southern Ningxia region in Loess Plateau. - Research of Soil and Water Conservation 12(3): 50-52: 179.

[16] Sun, T., Ma, Q. L., Jia, Z. Q., Li, Y. K., Wang, R. L., Zhang, X. J., Ma, J. M. (2015): Dynamic simulation of soil organic carbon pool of wolfberry forest in the secondary saline-alkali land in the arid regions in Jingtai, Gansu-take Jingtai electricity-powered irrigation zone as a case study. - Pratacultural Science 32(11): 1757-1766.

[17] Tang, J., Zhang, N., Li, Z. Y. (2011): Vertical distribution of soil organic carbon and carbon density under different land use types in western Jilin Province. - Journal of Jilin University (Earth Science Edition) 41(4): 1151-1156.

[18] Tang, J., Lou, Y., Li, N. (2012a): Soil moisture content and nitrogen impacts on soil organic carbon of saline-alkali paddy field under the effect of freeze-thaw. - Ecology and Environmental Sciences 21(4): 620-623.

[19] Tang, G. Y., Li, K., Sun, Y. Y., Zhang, C. H. (2012b): Effects of land uses on soil organic carbon and carbon pool management index. - Forest Research 24(6): 754-759.

[20] Tang, Z., Li, J. G., Li, H., Z. L. M., Li, Z. F., Lou, Y. L. (2014): Rapid responses of soil microbes and active organic carbon to eco-restoration in karst region. - Ecology and Environment Sciences 7: 1130-1135.

[21] Wang, Q., Wang, S., Feng, Z. W. (2005): Active soil organic matter and its relationship with soil quality. - Acta Ecologica Sinica 25(3): 513-519.

[22] Wu, J. F., Zeng, Y. H., Pan, X. H. (2013): Effects of rice straw returning mode on rice grain yield and soil carbon pool management index in double rice-cropping system. Chinese Journal of Applied Ecology 24(6): 1572-1578. 
[23] Wu, C. S., Xie, G. X., Zhang, M. K. (2015): Effects of agricultural practices and land use transformation on soil carbon management index. - Acta Agriculturae Zhejiangensis 27(4): 611-617.

[24] Xu, M. G., Yu, R., Sun, X. F., Liu, H., Wang, B. R., Li, J. M. (2006): Effects of longterm fertilization on labile organic matter and carbon management index (CMI) of the typical soils of China. - Plant Nutrition and Fertilizer Science 12(4): 459-465.

[25] Ya, P. S., Li, X. C., Wen, B. D. (2013): Spatiotemporal heterogeneity of soil total organic carbon and easily oxidizable organic carbon in the forest gaps of Pinus koraiensisdominated broadleaved mixed forest. - Journal of Soil and Water Conservation 27(6): 186-192.

[26] Zhang, H., Huang, L. H., Li, Y. Y. (2016a): Research and experience of rice planting in saline-sodic soil in Northeast China. - Soils and Crops 5(3): 191-197.

[27] Zhang, Y. J., Qian, H. H., Liu, K. P., Su, Y. R., Li, F. S. (2016b): Effect of fertilization on soil active organic carbon and carbon pool management index under maize/soybean intercropping condition. - Journal of South China Agricultural University 37(3):29-36.

[28] Zhang, P., Zhong, C., Zhou, Q., Tang, H. Y., Li, X. M., Li, P., Huang, G. Q. (2019): Effects of different winter planting patterns on carbon management index of paddy field. - Chinese Journal of Eco-Agriculture 27(08):1163-1171.

[29] Zhang, W. L., Kolbe, H., Zhang, R. L. (2020): Research progress of SOC functions and transformation mechanisms. - Scientia Agricultura Sinica 53(2): 317-331.

[30] Zhou, W., Wu, H. H., Zhang, Y. L. (2019): Improvement of determination method for soil labile organic carbon. - Chinese Journal of Soil Science 50(1): 76-81.

[31] Zou, X. M., Ruan, H. H., Fu, Y., Yang, X. D., Sha, L. Q. (2005): Estimating soil labile organic carbon and potential turnover rates using a sequential fumigation-incubation procedure. - Soil Biology \& Biochemistry 37(10): 1923-1928. 